\title{
Migration Narratives: An Introduction to Part I, Exemplars
}

\author{
Bill Fulford
}

The narratives on which the three chapters included in this first Part are based all involve migration. Many other scenarios are explored in later chapters. But as the contributions to this part illustrate, scenarios involving migration helpfully exemplify a number of aspects of the significance of cultural values in mental health.

In this chapter, we start by briefly introducing the migration narratives as told in full in their respective chapters. We then draw out four common themes about cultural values exemplified by these narratives, indicating how they play out across the book as a whole.

\subsection{The Migration Narratives}

We open with a narrative from the New World, specifically Canada. In his case study of eating disorders across cultures (chapter 3, 'Antonella: 'A Stranger in the Family'-A Case Study of Eating Disorders Across Cultures'), psychiatrist Vincenzo Di Nicola relates the story of a 24-year-old woman (Antonella) who was referred to him with a pre-existing eating disorder after she migrated to Canada from Italy to join her partner. Antonella remains, as Vincenzo graphically puts it, 'a stranger in the family' until she connects emotionally with the Canadian wilderness and finds cross-species identification as a breeder of husky dogs.

In the next chapter (chapter 4, 'The Role of Culture, Values and Trauma in Shaping Abnormal Bodily Experience in Migrants'), Italian philosopher-psychiatrist Massimiliano Aragona examines the role of culture, values and trauma in shaping

\footnotetext{
Authors

The editors with input from the contributors to Part I.

B. Fulford $(\bowtie)$

St Catherine's College, University of Oxford, Oxford, UK

(C) The Author(s) 2021

D. Stoyanov et al. (eds.), International Perspectives in Values-Based Mental

Health Practice, https://doi.org/10.1007/978-3-030-47852-0_2
} 
abnormal bodily experiences in migrants. Massimiliano draws on four contrasting narratives from his extensive experience as a clinician working with migrants: a 30-year-old Bangladeshi man (MD) who emigrated to Italy after a natural disaster at home leaving his wife and sons in Bangladesh; a 40-year-old Pakistani woman (Shafia) who arrived at a migrant reception centre in Italy with her two sons after being abandoned by her husband; a 43-year-old Ugandan woman (Pretty) who presented in a neuropsychiatry outpatient clinic with persistent and unexplained headache; and a 23-year-old Nigerian man (Godwin) who had fled to Italy when his father died to avoid taking up his preordained role in his home village as a fetish priest.

With the final chapter in this Part (chapter 5, 'Premorbid Personality and Expatriation as Possible Risk Factors for Brief Psychotic Disorder: A Case Report from Post-Soviet Bulgaria'), we move from Italy to post-Soviet Bulgaria, with psychiatrists, Stefan Popov and Mladen Mantarkov's exploration of the interactions between premorbid personality and expatriation in the aetiology of brief psychotic disorder. They present the story of a 29-year-old single Bulgarian woman (Alice) who developed psychotic symptoms while living and working alone in Germany. Like many others, Alice had migrated to Germany after the fall of the Soviet regime in Bulgaria in the hope of finding a better life. Once she settled back in Bulgaria, her psychotic symptoms resolved. Popov and Mantarkov speculate on the possible wider significance of the protective Bulgarian cultural values from which Alice benefitted in recovering her mental health.

\subsection{Common Theme 1: Cultural Values May Have a Negative Role Acting as Factors in the Causes and Presentation of Mental Health Issues}

Cultural factors are widely recognised to be important in the causes and presentation of mental health issues. With eating disorders, as Vincenzo Di Nicola notes in chapter 3, this recognition extends to the role specifically of cultural values. The prevalence of eating disorders, as he describes, varies widely between cultures (arguably) corresponding with variations in cultural values-the cultural importance of 'fashionable slimness', for example, has been identified with the greater prevalence of eating disorders among women in industrialised societies. Not only that, but the form these disorders take appears to vary between cultures. Vincenzo Di Nicola has coined the term 'anorexia multiforme' to capture the extent of this culturally driven variation in clinical presentations of anorexia.

With many other mental health issues, however, while the importance of cultural factors has been recognised, the impact specifically of cultural values has by and large been overlooked. Massimiliano Aragona (chapter 4) makes this point in respect of somatisation disorders. The roles of trauma and culture in shaping these 
disorders, he suggests, are well recognised, but, again, the role specifically of cultural values has been relatively neglected. The four narratives he presents are aimed at remedying this neglect for somatisation disorders. Chapter 5 makes a similar point in respect of brief psychotic episodes. Stefan Popov and Mladen Mantarkov's story of Alice brings out the hitherto neglected role of cultural and other values interacting with personality and life events in provoking psychotic breakdowns.

Taken together therefor the narratives presented in the three chapters of Part I illustrate the impact not just of culture but specifically of cultural values on the causes and presentation of three representative kinds of mental health issue. The importance of cultural values these narratives thus suggest is not limited to a narrow group of 'culture-bound disorders'. It is generic. Other chapters in the book extend the range of conditions that are demonstrably impacted by cultural values still further: eating disorders and psychosis continue to figure strongly in the book, but to these are added, in Part III alone, for example, identity disorders in adolescence (chapter 16, 'Cross-Cultural Factors and Identity in Adolescence'), depression and infanticide (chapter 17, 'Multidisciplinary Teamwork and the Insanity Defence: A Case of Infanticide in Iraq') and alcoholism (chapter 19. 'Alcohol Use Disorder in a Culture that Normalizes the Consumption of Alcoholic Beverages: The Conflicts for Decision-Making'). Many other examples are to be found elsewhere in the book.

\subsubsection{A Note on Diagnostic Categories}

In noting the role of cultural values across these diagnostic categories, we should not be taken as endorsing the categories in question, still less the supposedly 'value free' descriptive terms by which they are standardly defined. To the contrary, a number of chapters later in the book illustrate the role of cultural and other values in delineating the boundary between health and illness: chapters 13, 'Spiritual, Religious and Ethical Values in a Suicidal Individual' and 14, 'Cultural Values, Religion and Psychosis: Five Short Stories', for example, are concerned with the boundary between mental disorder and spiritual experience, and chapter 17, 'Multidisciplinary Teamwork and the Insanity Defence: A Case of Infanticide in Iraq' is concerned with the scope of the 'insanity defence'.

We return below to the relationship between cultural values and mental health science as reflected in contemporary descriptive classifications of mental health issues (see common theme 3). But our point here as we have said is not to endorse (nor indeed to critique) current diagnostic categories. It is rather to note that once we start looking for them, prompted as we have been by the migration narratives presented in this Part, we find cultural values evident across the board in mental health. 


\subsection{Common Theme 2: Cultural Values May Also Play Positive Roles Acting as Protective Factors for Mental Health}

The news about cultural values, though, is, as they say, 'not all bad'. Yes, cultural values may be important in provoking and shaping mental health issues: Massimiliano Aragona's four narratives in chapter 4 illustrate these negative influences all too well. But cultural values may also exert positive influences.

These positive influences are evident in the protective roles of cultural values exemplified particularly by the narratives in the other two chapters in this Part. Vincenzo Di Nicola's Antonella (chapter 3) was only able to move towards recovery when she found a sense of identity in her role as a breeder of Husky dogs in the Canadian wilderness. Stefan Popov and Mladen Mantarkov (chapter 5) note that Alice's sustained recovery from her psychotic symptoms once she was allowed to leave Germany and return home, may well have resulted from the positive and supportive work environment prevailing in her native Bulgaria. They speculate that similar cultural values may have wider significance as protective factors in mental health.

As with the negative influences of cultural values, their positive roles are reflected across the book as a whole. There is no scope for romanticism here. Cultural values may have highly negative effects. The recovery narratives with which Part III concludes (chapters 22, 'Three Points in Time: How Values and Culture Affected My Life, Madness and the People Around Me' and 23, 'Recovery and Cultural Values: On Our Own Terms (A Dialogue)') illustrate these negatives influences all too well. But these same narratives also show that cultural values may have positive impacts as well. This mix of positive and negatives is also evident elsewhere in the book. African cultural attitudes for example may be responsible for male suicide (chapter 10, 'African Personhood, Humanism, and Critical Sankofaism: The Case of Male Suicide in Ghana') but African Mythopoetry (chapter 11, 'Madness, Mythopoetry and Medicine') heals; Brazilian values may normalise problem drinking (chapter 19, 'Alcohol Use Disorder in a Culture that Normalizes the Consumption of Alcoholic Beverages: The Conflicts for Decision-Making') but Brazilian carnival liberates (chapter 18, 'Colonial Values and Asylum Care in Brazil: Reclaiming the Streets through Carnival in Rio de Janeiro') and so on.

\subsubsection{Balancing Positives and Negatives}

Balancing positives and negatives is important. It is natural that clinicians should focus on the negatives - it is after all with the negatives of problem situations that clinicians are concerned day-to-day. But in mental health, understanding the balance of positives and negatives is important to effective care: Roz Austin's two contrasting narratives (chapter 34, 'Values-Based Practice When Engaging with Voice-Hearers'), of Paul and Mary, make the point about the need for balance in relation to voice hearing. When it comes to recovery in mental health, furthermore, 
it is the positives that are often key. This is true for example in the three autobiographical recovery narratives in this book (chapters 22, 'Three Points in Time: How Values and Culture Affected My Life, Madness and the People Around Me', 23 'Recovery and Cultural Values: On Our Own Terms (A Dialogue)' and 32, 'Discovering Myself, a Journey of Rediscovery'). The importance in recovery of the StAR values of values-based practice (Strengths, Aspirations and Resources) is correspondingly recognised in UK good practice guidance. ${ }^{1}$

Again, the point exemplified by the narratives in this Part is about balance. Cultural values may be inimical to recovery but they may be the key to recovery as well. The challenge is to recognise both kinds of influence and to balance them in a way that works for the individual concerned. It is to this challenge that the resources for training in values-based practice illustrated by the contributions to Part V are centrally directed.

\subsection{Common Theme 3: Narrative Understanding of Cultural Values}

The importance of narrative understanding of cultural values - the third theme exemplified by the contributions to Part I-was anticipated by what we said about inverting hierarchies in our introduction to values-based practice in chapter 1, Sect. 1.5.3. ${ }^{2}$ Where narratives, as we put it, come at the bottom of the evidence hierarchy, they come at the top of the corresponding hierarchy for values.

The rationale for this inversion of hierarchies is evident in the contributions to Part I. Each of the narratives presented speaks to us directly. The validity of Antonella's story for example (chapter 3, 'Antonella: 'A Stranger in the Family' -A Case Study of Eating Disorders Across Cultures') does not depend on the availability of a randomised controlled trial of the impact of the Canadian wilderness on personal identity (still less does it depend on there being available a meta-analysis of multiple such trials). In the context of her story, this speaks to us directly. We understand Antonella. We understand her as one human being understands another. This is the power of narrative.

It is the need for narrative understanding that underpins the importance of many of the philosophical resources explored in Part II of this book. Aesthetics (chapter 7, 'The Will to Beauty as a Therapeutic Agent: Aesthetic Values in the Treatment of Addictive Disorders') and phenomenology (chapters 8, 'Anorexia as Religion: Ocularcentrism as a Cultural Value and a Compensation Strategy in Persons with Feeding and Eating Disorders' and 9, 'Ethos, Embodiment, and Psychosis: Losing One's Home-Identity Stakes') are both directly concerned with understanding as distinct from explanation. So, too, is hermeneutics, with its intriguing links with the

\footnotetext{
${ }^{1}$ The StAR values of values-based practice were derived from co-produced guidance on best practice in mental health assessment sponsored by the UK Department of Health [1].

${ }^{2}$ See especially Fig. 3, chapter 1, 'Surprised by Values: An Introduction to Values-Based Practice and the Use of Personal Narratives in this Book'.
} 
Critical Sankofaism of African philosophy (chapter 10, 'African Personhood, Humanism, and Critical Sankofaism: The Case of Male Suicide in Ghana'). The storytelling tradition of African Mythopoetry (chapter 11, 'Madness, Mythopoetry and Medicine') directly exemplifies the power of narrative understanding. All these resources furthermore come together to good effect in exploring specific aspects of the role of cultural values in mental health: the impact of cultural values on body image for example (chapter 12, 'Inside and Out: How Western Patriarchal Cultural Contexts Shape Women's Relationships with Their Bodies') and their role in delineating psychopathological and spiritual experiences (chapters 13, 'Spiritual, Religious and Ethical Values in a Suicidal Individual' and 14, 'Cultural Values, Religion and Psychosis: Five Short Stories').

Our selection of topics in Part II, as with other areas of the book, is far from exhaustive. There are whole areas of contemporary philosophy that deserve mention. From the history of ideas, for example, we could have included Karl Jaspers' distinction between meaningful understanding and causal explanation [2] and how this became one of the building blocks of his seminal General Psychopathology [3]. Relevant too are whole areas of the philosophy of mind: work on 'other minds' for example is all about our capacity for understanding what is going on in someone else's mind. The latter, furthermore, reinforcing the theme of partnership, is one of the many areas of contemporary philosophy where psychopathology informs philosophy as well as philosophy psychopathology ${ }^{3}$ (for examples, see [4]).

So understood, the importance of narrative understanding of values is an aspect of the essential partnership between values-based practice and evidence-based practice outlined in chapter $1 .{ }^{4}$ It is to the importance of this partnership as reflected in the contributions to this book that we turn next.

\subsection{Common Theme 4: The Partnership Between Cultural Values and Mental Health Science}

Whereas the first three themes exemplified by the contributions to Part I have all been evident in what was said, the fourth theme is evident in what has not been said. It is evident in the fact that in drawing out the importance of cultural values in mental health, the contributors to Part I have said nothing against the importance of science in mental health.

Well, some may respond, they would say that, wouldn't they! The authors of the three chapters making up Part I are all psychiatrists, and psychiatry is committed to a scientific view of mental health issues. But that is precisely our point. Yes, psychiatry - along with other mental health disciplines such as psychology-is committed to a scientific understanding of mental health. This is indeed one of the key

\footnotetext{
${ }^{3}$ See, for example, work on theory of mind and autism [4] and on deafness [5] and, for a different view [6].

${ }^{4}$ See in particular the first part of Sect. 3, chapter 1, 'Surprised by Values: An Introduction to Values-Based Practice and the Use of Personal Narratives in this Book'.
} 
cultural values of psychiatry as a medical discipline. In the terms of chapter 1 , 'Surprised by Values: An Introduction to Values-Based Practice and the Use of Personal Narratives in this Book', science matters or is important to psychiatry as a medical discipline. The authors of the chapters in Part I are in this respect well placed to represent the cultural values of psychiatry: Vincenzo Di Nicola is indeed a leading international figure in the medical scientific discipline of transcultural psychiatry.

Our point therefor, the point of the final theme to be taken from the contributions to Part I, is that there is no contradiction between, on the one hand, recognising the importance of cultural values in mental health and, on the other hand, recognising the importance equally of mental health science.

This 'no contradiction' conclusion is consistent with the partnership model of the relationship between values and science in values-based practice described in chapter $1 .{ }^{5}$ The contributions to Part IV, Science, later in this book, fill out this partnership model. The early chapters of Part IV between them illustrate the impact of cultural values on the three principles of values-based practice by which (as described in chapter 1) its relationship with evidence-based practice is characterised: the Two Feet principle (chapter 25, 'A Cross-Cultural Values-Based Approach to the Diagnosis and Treatment of Dissociative (Conversion) Disorders'), the Squeaky Wheel principle (chapters 26, 'Treatment of Social Anxiety Disorder or Neuroenhancement of Socially Accepted Modesty? The Case of Ms. Suzuki' and 27, 'Nontraditional Religion, Hyper-Religiosity, and Psychopathology: The Story of Ivan from Bulgaria') and the Science Driven principle (chapter 28, 'Journey into Genes: Cultural Values and the (Near) Future of Genetic Counselling in Mental Health'). These three principles together characterise how values-based practice 'links science with people'. The remaining chapters in Part IV reflect the importance of the wider 'values tool kit' 6 of healthcare in linking science with people, illustrated respectively by the African indaba (chapter 29, 'Policy-Making Indabas to Prevent "Not Listening": An Added Recommendation from the Life Esidimeni Tragedy'), transcultural ethics (chapter 30, 'Covert Treatment in a Cross-Cultural Setting') and anthropology (chapter 31, 'Discouragement Towards Seeking Health Care of Older People in Rural China: The Influence of Culture and Structural Constraints').

Migration narratives, to return to the focus of this Part, provide a case in point of the Squeaky Wheel principle. It is through migration that cultural values are most likely to come into conflict and it is where values come into conflict that they are drawn to our attention-it is when they come into conflict that in the metaphor of the Squeaky Wheel, the values in question 'squeak'. This is why migration narratives of the kind presented in this Part are particularly helpful in drawing out and making explicit the operation of cultural values in mental health. But to extend the

\footnotetext{
${ }^{5}$ See footnote 4 above.

${ }^{6}$ See the final part of Sect. 3, and Table 2, chapter 1, 'Surprised by Values: An Introduction to Values-Based Practice and the Use of Personal Narratives in this Book'.
} 
Squeaky Wheel metaphor, just as the wheel is still there and important even when it is not squeaking, so, too, are cultural values there and important across the board in mental health.

\subsection{Conclusions}

We have discussed four themes about the role of cultural values in mental health exemplified by the migration narratives described in the three chapters making up Part I of this book. Taken together, these narratives indicate (1) that cultural values have a negative role in mental health, impacting as they do on the causes and presentation of mental health issues well beyond the limits of traditionally defined 'culture-bound' syndromes; (2) that cultural values also have a positive role as protective factors, notably in contributing to recovery in mental health; (3) that narrative understanding is as important for understanding values as randomised controlled trials and other empirical resources are important for understanding evidence; and (4) that the relationship between values (cultural and otherwise) and science in mental health is best understood as one of partnership.

We have indicated how these four themes play out across and are further developed in later parts of the book. The importance of narrative understanding is reflected in the diverse contributions to Part II, Theory. The impact (positive as well as negative) of cultural values on mental health is reflected particularly in Part III, Practice. The partnership between values and science is reflected in Part IV, Science. And, lest it be thought we have neglected Part V, Training, it was with the training tasks presented by all four themes in mind that we gave our introduction to that Part (chapter 33), the title 'Training for Task'.

We recognise that a partnership model of the relationship between values and science is far from universally accepted. There are many, we openly acknowledge, who from adverse personal experiences reject outright any role whatsoever for science in mental health. There are many others, we also recognise, who in defence of what they take to be a scientific perspective, reject outright any role whatsoever for values in mental health. The partnership model adopted here will satisfy neither of these extremes. It is however consistent with the framing of values within valuesbased practice as 'linking science with people'. And it is through this frame, we believe, it is through the frame of values as linking science with people that a deeper understanding of cultural values will contribute to improvements in mental health care.

\section{References}

1. National Institute for Mental Health in England (NIMHE) and the Care Services Improvement Partnership. 3 Keys to a shared approach in mental health assessment. London: Department of Health; 2008. Also available as a free full-text download from the Collaborating Center for Values-based Practice at http://valuesbasedpractice.org/More-about-VBP/Full-text-downloads. 
2. Jaspers K. Causal and meaningful connexions between life history and psychosis. Ch. 5. In: Hirsch SR, Shepherd M, editors. Themes and variations in European psychiatry. 1974. Bristol: John Wright and Sons Ltd; 1913. p. 80-93.

3. Jaspers K. Allgemeine Psychopathologie. Berlin: Springer; 1913. (Trans. Hoenig J, Hamilton MW. General psychopathology. Chicago: University of Chicago Press; 1963. New edition (two volumes, paperback), with a Foreword by Paul R McHugh, Baltimore: The Johns Hopkins University Press; 1997.

4. Avramides A. Other minds. London: Routledge; 2000.

5. Peterson CC, Siegal M. Insights into theory of mind from deafness and autism. Ch 5 . In: Coltheart M, Davies M, editors. Pathologies of belief. Oxford, Blackwell Publishers; 2000.

6. Hobson RP. Against the 'theory of mind'. Br J Dev Psychol. 1991;9:33-51.

Open Access This chapter is licensed under the terms of the Creative Commons Attribution 4.0 International License (http://creativecommons.org/licenses/by/4.0/), which permits use, sharing, adaptation, distribution and reproduction in any medium or format, as long as you give appropriate credit to the original author(s) and the source, provide a link to the Creative Commons license and indicate if changes were made.

The images or other third party material in this chapter are included in the chapter's Creative Commons license, unless indicated otherwise in a credit line to the material. If material is not included in the chapter's Creative Commons license and your intended use is not permitted by statutory regulation or exceeds the permitted use, you will need to obtain permission directly from the copyright holder.

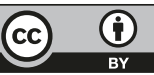

